\title{
GESTÃO ESCOLAR NO ENSINO MÉDIO APÓS A REFORMA*
}

\author{
GESTIÓN ESCOLAR EN LA ENSEÑANZA MEDIO DESPUÉS DE LA
}

\author{
REFORMA
}

\author{
Giovanna Amorim Maciel ${ }^{1}$ \\ Fabio Perboni ${ }^{2}$ \\ Elis Regina Viegas ${ }^{3}$
}

\begin{abstract}
RESUMO: Este trabalho tem por objetivo analisar a gestão escolar no nível do ensino médio a partir do modelo de gestão democrática estabelecida pelo arcabouço normativo-legal brasileiro, após a reforma do ensino médio, sancionada pela Lei ${ }^{\circ} 13.415$, de 16 de Fevereiro de 2017. A opção metodológica deu-se pelo levantamento bibliográfico dentro de uma abordagem qualitativa de interpretação da produção teórica sobre a gestão no espaço educacional. Com o objetivo de investigar a gestão a partir da reforma, o texto está estruturado da seguinte forma: primeiro, adentra-se ao papel da gestão, observando os aspectos democráticos que a definem; segundo, apresentam-se as orientações normativo-legais que norteiam a gestão do ensino médio anterior à reforma, em um comparativo com as novas diretrizes e, por fim, na terceira e última parte trazemos as considerações finais e as perspectivas da pesquisa no que diz respeito a novas metas. A gestão das unidades escolares é a instância de organização e administração voltada à atividade da educação básica, abarcando suas etapas e modalidades. Tendo definido seu âmbito de atuação, a própria legislação - CF (BRASIL, 1988) e LDB (BRASIL,1996) - que a determina, também estabelece como princípio que norteia a gestão democrática da educação pública. Diante disso, as orientações percebidas nos documentos nos possibilita enxergar caminhos diversos para o planejamento da estrutura de aprendizagem realizada nas instituições escolares do Ensino Médio e encontrar meios de efetivar a gestão democrática definida nas leis.
\end{abstract}

Palavras chaves: Gestão Democrática, Princípios Democráticos. Reforma do Ensino Médio.

RESUMEN: Este trabajo tiene por objetivo analizar la gestión escolar a nivel de la enseñanza media a partir del modelo de gestión democrática establecida por el marco normativo-legal brasileño, tras la reforma de la enseñanza media, sancionada por la Ley 13.415, de 16 de febrero de 2016. La opción metodológica se dio por el levantamiento bibliográfico dentro de un abordaje cualitativo de interpretación de la producción teórica sobre la gestión en el espacio educativo. Con el objetivo de investigar la gestión a partir de la reforma, el texto está estructurado de la siguiente forma: primero, se adentra en el papel de la gestión, observando los aspectos democráticos que la definen; En segundo lugar, se presentan las orientaciones

\footnotetext{
*Artigo apresentado como requisito para conclusão do curso de Licenciatura em Pedagogia, junto a Faculdade de Educação da Universidade Federal da Grande Dourados (UFGD), sob a orientação do Prof. Dr. Fábio Perboni, professor adjunto da Faculdade de Educação da Universidade Federal da Grande Dourados. Coorientação da Prof ${ }^{a}$ Mestre Elis Regina Viegas. Docente responsável pela disciplina de Trabalho de Graduação II Prof ${ }^{a}$. Doutoranda Míria Izabel Campos (miriacampos@ufgd.edu.br).

${ }^{1}$ Discente do $8^{\circ}$. Semestre de Pedagogia da Faculdade de Educação da Universidade Federal da Grande Dourados (FAED/UFGD).E-mail: giomaciel@gmail.com

2 Professor adjunto da Faculdade de Educação da Universidade Federal da Grande Dourados. E-mail: fabioperboni@ufgd.edu,br.

3 Doutoranda em Educação, Programa de Pós-Graduação em Educação/UFGD. E-mail: profelisregina@hotmail.com
} 
normativo-legales que orientan la gestión de la enseñanza media anterior a la reforma, en un comparativo con las nuevas directrices y, finalmente, en la tercera y última parte traemos las consideraciones finales y las perspectivas de la investigación en lo que dice respecto a nuevas metas. La gestión de las unidades escolares es la instancia de organización y administración orientada a la actividad de la educación básica, abarcando sus etapas y modalidades. Habiendo definido su ámbito de actuácion la propia legislación - CF (BRASIL, 1988) e LDB (BRASIL, 1996) - que la determina, también establece como principio que orienta la gestión democrática de la educación pública. Por lo tanto, las orientaciones percibidas en los documentos nos posibilitan ver caminos diversos para la planificación de la estructura de aprendizaje realizada en las instituciones escolares de la Enseñanza Media y encontrar medios para hacer efectiva la gestión democrática definida en las leyes.

Palabras claves: Gestión Democrática. Principios Democráticos. Reforma de la Enseñanza Media.

\section{Introdução}

Este artigo é resultado de uma proposta de Trabalho de Graduação, que teve como intuito apresentar uma reflexão sobre Gestão Democrática no âmbito da reforma do ensino médio. A questão da gestão escolar se faz presente como elemento potencial de promoção e participação dos envolvidos no processo educacional, com a atribuição de buscar propostas deliberativas de efetivação e intervenção no espaço institucional de atendimento escolar.

Assume-se como perspectiva de análise - levantamento bibliográfico e pesquisa documento, conforme orientação de Cervo, Bervian e Silva (2007) - a concepção de gestão democrática, tendo em conta o ordenamento legal brasileiro - Constituição Federal Brasileira (CF) de 1988 e Lei de Diretrizes e Bases da Educação Nacional (LDB) Lei nº 9.394 de 1996 -, e a produção acadêmica da área (PARO, 2007 e 2010; LIBÂNEO, OLIVEIRA e TOSCHI, 2010; CURY, 2002; VEIGA, 2002 e 2007; entre outros).

A partir disso, tem-se como objetivo geral: investigar como a percepção de gestão democrática se apresenta nos documentos-normativos que orientam as mudanças no cenário do ensino médio pós-reforma no Brasil. E, como objetivos específicos: identificar o papel da gestão democrática e os aspectos que a definem a partir da arcabouço legal brasileiro; caracterizar as orientações normativo-legais que norteiam a gestão escolar na etapa do ensino médio anterior e pós reforma; analisar os elementos da reforma do ensino médio que marcam a gestão democrática no contexto escolar.

Embora, saibamos que o espaço educacional é permeado por condições contraditórias, haja vista que, historicamente, seu contexto é marcado por tomadas de decisões verticalizadas e formas de ações centralizadas, que em diferentes momentos impedem as interações com a comunidade local, bem como inviabiliza a autonomia para gestar de modo adequado as diversidades sociais, culturais e econômicas. 
Todavia, também entendemos que as atuais reflexões sobre a gestão nas escolas consistem na compreensão de uma concepção de poder a serviço dos propósitos traçados e almejados coletivamente.

No cotidiano da sociedade vemos a reivindicação de uma escola democrática que atenda de forma eficiente as necessidades educacionais da comunidade. A escola é assumida como espaço de mediação e troca de conhecimentos, nesse sentido a proposta gestada deve prever uma ação preocupada com o envolvimento e a participação efetiva do coletivo.

Nesse espaço existem muitos fatores que contribuem para o seu "bom funcionamento" (SILVA, 2007; PARO, 2010), com o intento de alcançar uma aprendizagem de qualidade, por meio do diálogo contínuo, sejam: participação ativa da comunidade interna e externa; Projeto Político-Pedagógico elaborado coletivamente; Conselho Escolar e Didático-Pedagógico, Associação de Pais e Mestres (APM); descentralização das decisões; formação/educação baseada nos meios e não só nos fins; educação de qualidade fundamentada na criticidade e na criatividade; infraestrutura e currículo adequados as demandas; formação inicial e continuada dos profissionais que atuam nas unidades escolares; entre outras possibilidades.

A organização e a gestão referem-se ao "conjunto de normas, diretrizes, estrutura organizacional, ações e procedimentos que asseguram a racionalização do uso de recursos humanos, materiais, financeiros e intelectuais assim como a coordenação e o acompanhamento do trabalho" (LIBÂNEO; OLIVEIRA; TOSCHI, 2010, p.293), essas funções mediante várias ações é o que denomina gestão, ou seja, um sistema organizacional que mobiliza diferentes meios com um objetivo comum.

Para isso, é fundamental que a gestão escolar seja permeada por princípios democráticos de ação. Assim, compreender o seu significado constitui-se um dos primeiros passos do processo:

Gestão nos lembra gestação, gerir, dar a vida, e, como tal, nos agrada, porque, em se tratando da escola, nosso objetivo principal é fazer com que a vida dos seres humanos que passam por ela [escola] se torne mais promissora, mais digna, mais justa, mais humana. Isto para nós é mais viver, mais gerir, é mais felicidade. Nesse sentido, gestão vai além do seu conceito primeiro que diz respeito à ação de dirigir, administrar (SILVA, 2007, p. 22).

Ao adentrarmos este universo cheio de significados e, também, tão importante para a formação do professor/gestor, percebem-se caminhos diversos na estrutura organizativa administrativa com vista à aprendizagem (espaços, tempos, currículos) realizada nas instituições escolares. 
Por isso mesmo, a assunção da pesquisa no âmbito acadêmico é, portanto, parte indispensável para despertar reflexões e estimular a criticidade, bem como colaborar com os conhecimentos que compõem o campo de atuação docente por meio da articulação entre teoria e prática. Tal exercício nos permite apreender diferentes posicionamentos, bem como as funções atribuídas aos gestores frente à busca de uma escola democrática.

Diante disso, o texto está estruturado da seguinte forma: primeiro, adentra-se ao papel da gestão, observando os aspectos democráticos que a definem; segundo, apresentam-se as orientações normativo-legais que norteiam a gestão do ensino médio anterior à reforma, em um comparativo com as novas diretrizes e, por fim, na terceira e última parte trazemos as considerações finais e as perspectivas da pesquisa no que diz respeito a novas metas. A gestão das unidades escolares é a instância de organização e administração voltada à atividade da educação básica, abarcando suas etapas e modalidades.

\section{0 papel da gestão escolar: aspectos da gestão democrática a partir das orientações normativas}

A gestão democrática da educação pública foi estabelecida como princípio da CF de 1988 e reafirmada na LDB de 1996. Tais imperativos fixaram incumbências dos entes federativos para sua concretização, deixando aos sistemas de ensino a tarefa de definir e/ou disciplinar essa forma de gestão (PARO, 2007). Desse modo, no âmbito legal, a gestão democrática estabeleceu-se como a concepção que deve prevalecer no sistema educacional brasileiro.

De tal modo, a gestão das unidades escolares é a instância da gestão educacional voltada à atividade da educação básica, abarcando suas etapas e modalidades. Isso significa "[...] um nível de ação clivada tanto pelos contextos sociais locais, quanto pelo contexto mais global dos sistemas de ensino e das políticas públicas que afetam o conjunto das instituições formais de ensino" (GIGLIO; JACOMINI, 2013, p.35).

Nesse sentido, apreendemos que a gestão democrática é um princípio normativo-legal da educação, porém, buscamos na literatura o conceito do termo, ou seja, seu significado. Assim, recorremos a Cury (2002), a gestão democrática consiste em ato de administrar um bem público com a participação da sociedade em geral, de forma direta e mediada por conselhos em todos os âmbitos da educação, propiciando a tomada de decisão baseada em participação e deliberação pública.

Nessa mesma direção, Paro (2007) informa que a participação é o elemento central da concepção de gestão democrática. Para ele, esta consiste no ato de se administrar com a real 
participação nas decisões - no caso da escola esse processo envolve professores, funcionários, pais e alunos. A participação da comunidade interna e externa da unidade escolar nas deliberações escolares e na construção de intenções educativas necessita dar-se em consonância com os anseios da comunidade como um todo, isto é, com objetivos e intenções comuns.

O exposto evidencia, de acordo com Libâneo, Oliveira e Toschi (2010, p.330) que o trabalho do gestor deve ter como princípio ações democráticas. Para os autores a gestão escolar, "além de uma das funções do processo organizacional, é um imperativo social e pedagógico". Este significado vai além da mobilização das pessoas para a realização eficaz das atividades, pois implica intencionalidade, definição de um rumo educativo, tomada de posição frente os objetivos escolares, sociais e políticos.

Sobre a tomada de posição, Paro (2010) em outro momento aborda a prática da gestão escolar a partir da ação do diretor e do coordenador (gestores), tendo em vista os papeis que lhes são atribuídos: administrativo e pedagógico. O autor contribui no entendimento do real papel que estes profissionais devem realizar na escola, em razão de reconhecer a função desses gestores para o "bom funcionamento da instituição", ainda que essas funções ainda passem por dificuldades na prática cotidiana. Cada profissional tem, particularmente, na organização escolar funções específicas, mas na dinâmica da gestão democrática, estes devem dialogar e trabalhar coletivamente.

O autor reforçar os pressupostos levantados ao longo do texto, ao apontar que a gestão só é democrática, quando se permite que os sujeitos participem da construção da proposta educativa. Libâneo, Oliveira e Toschi (2010), complementam ao assinalar que esse processo decorre da viabilização das condições, dos meios e recursos necessários para funcionamento da escola; do envolvimento das pessoas no trabalho, por meio da participação, da avaliação contínua e do estímulo e acompanhamento da participação; assim como, a realização da aprendizagem para todos os alunos.

Tal processo decorre do caráter de intencionalidade presente nas ações educativas. "Intencionalidade significa a resolução de fazer algo, de dirigir o comportamento para aquilo que tem significado para nós" (LIBÂNEO; OLIVEIRA; TOSCHI, 2010, p. 331). Esta concepção projeta-se nos objetivos que, por sua vez, orientam a atividade humana, dando rumo, a ação dos gestores escolares. Na escola a intencionalidade motiva a equipe escolar à busca deliberada, consciente, planejada, de integração e unidade de objetivos e ações, além de consenso sobre normas e atitudes comuns.

Diante disso, podemos perceber que, essencialmente, a gestão escolar lida com a organização administrativa e pedagógica que envolve um conjunto de diversos aspectos: 
administrativos, legais, pedagógicos e, sobretudo, de ações e/ou projetos educativos da instituição escolar. Tais aspectos são articuladores do trabalho pedagógico e que exige, fundamentalmente, clareza sobre a intenção educacional almejada.

Desse modo, a organização do trabalho pedagógico tem início nas propostas de composição de espaços e tempos, nas determinações que abarcam a disposição de recursos para propiciar o atendimento às demandas; nas ações internas e externas a instituição que envolve professores e funcionários; nas práticas de planejamento e de acompanhamento do Projeto Político Pedagógico (PPP); na formação permanente do pessoal da instituição; no estímulo à participação da comunidade escolar na gestão; e no funcionamento dos canais institucionais de participação (GIGLIO; JACOMINI, 2013).

Assim, consideramos que a gestão escolar vai além as ações de planejar, coordenar, dirigir e avaliar, pois implica saberes e conhecimentos individuais e coletivos permanentemente renovados para o enfrentamento dos desafios cotidianos (FARIA; FINCO, 2011).

Se há fluidez na organização e administração por parte da gestão escolar, há espaço de autonomia interna na instituição para conceber os espaços, tempos, currículo como ferramentas de trabalho e oportunidades a serem exploradas em favor do projeto pedagógico (SALLES; FARIA, 2012). Vale destacar, de acordo com as autoras, as possibilidades já exploradas por muitas escolas, o estímulo à criação e experimentação de práticas construídas nas próprias instituições. Propostas locais, que surgem das necessidades da própria escola, fazem nascer o sentido da educação para além do conteúdo programado, o que confere valor aos saberes que são discutidos entre os sujeitos da escola.

Portanto, ao tratarmos de gestão escolar nos referimos a uma dimensão que pode revelar a relação das práticas de mediação ações administrativas permeadas ou não por intenções democráticas.

Por ser um trabalho complexo, a gestão escolar requer conhecimento e adoção de alguns princípios básicos, cuja aplicação deve se subordinar às condições concretas da escola (LIBÂNEO; OLIVEIRA; TOSCHI, 2010). Os autores propõem alguns princípios de gestão baseados no viés democrático:

[...] autonomia da escola e da comunidade educativa; relação orgânica entre direção e a participação dos membros da equipe escolar; envolvimento da comunidade no processo escolar; planejamento das atividades; formação continuada para o desenvolvimento do pessoal e profissional dos integrantes da comunidade escolar; utilização das informações concretas e análise de cada problema em seus múltiplos aspectos, com ampla democratização das informações; avaliação compartilhada; relações humanas produtivas e criativas, assentadas em uma busca de objetivos comuns (Ibid., p.333). 
Nesse norte, apreendemos que a função das instituições de educação se apresenta dentro do projeto de sociedade democrática desenhado pela $\mathrm{CF} / 1988$ (art.3 ${ }^{\circ}$, inciso I), com responsabilidade no desempenho de um papel ativo na construção de uma sociedade livre, justa, solidária e socioambientalmente orientada, conforme apontado no Parecer CNE/CEB no 07 (BRASIL, 2010a) e Resolução nº 04, ambas de 2010.

De fato, as Diretrizes Curriculares Nacionais Gerais para Educação Básica, definidas pela Resolução $n^{\circ}$ 04, artigo 2ª incisos I e II (BRASIL, 2010b, p. 63), objetivam:

I - sistematizar os princípios e as diretrizes gerais da Educação Básica contidos na Constituição, na Lei de Diretrizes e Bases da Educação Nacional (LDB) [entre outros a gestão democrática] e demais dispositivos legais, traduzindo-os em orientações que contribuam para assegurar a formação básica comum nacional, tendo como foco os sujeitos que dão vida ao currículo e à escola;

II - estimular a reflexão crítica e propositiva que deve subsidiar a formulação, a execução e a avaliação do projeto político-pedagógico [instrumento democrático de participação] da escola de Educação Básica.

Estabelecido isso, compreende-se a escola como espaço de emancipação reflexiva e crítica, frente às exigências (da sociedade atual) em relação a educação básica, o que demanda mudanças conjunturais: "priorizar processos capazes de gerar sujeitos inventivos, participativos, cooperativos, preparados para diversificadas inserções sociais, políticas, culturais, laborais e, ao mesmo tempo, capazes de intervir e problematizar as formas de produção e de vida", ou seja, a escola tem como "desafio de sua própria recriação" (BRASIL, 2010a, p.16).

Apresenta-se assim, o PPP como instrumento inicial de mudança, por ser designado na LDB/1996 como proposta que representa mais do que um documento. É um dos "meios de viabilizar a escola democrática e autônoma para todos, com qualidade social”, em razão de a autonomia pressupor "liberdade e capacidade de decidir a partir de regras relacionais" (BRASIL, 2010a, p.47). O PPP é igualmente entendido como plano orientador das ações da instituição e definidor de metas almejadas para o desenvolvimento e aprendizagem da instituição escolar.

Art. 14. Os sistemas de ensino definirão as normas da gestão democrática do ensino público na educação básica, de acordo com as suas peculiaridades e conforme os seguintes princípios:

I - participação dos profissionais da educação na elaboração do projeto pedagógico da escola;

II - participação das comunidades escolar e local em conselhos escolares ou equivalentes (BRASIL, 1996). 
Diante disso, entende-se que o PPP esta intimamente articulada a um compromisso com os interesses sociopolítico e coletivo para a sociedade, tendo interesses reais, adotando uma prática educativa consciente e organizada tendo em vista o futuro (VEIGA, 2008). Sendo assim, o PPP é instrumento de construção coletiva e ao observamos as necessidades apresentadas à dinâmica da educação básica, é possível perceber que a constituição da gestão escolar não diz respeito apenas a seu aspecto espacial-administrativo, mas também um ambiente que implica a maior e menor integração de vários aspectos ou dimensões, que sempre estarão em interação.

Tendo os instrumentos para orientar os processos de gestão, entre eles o PPP, temos os Parâmetros Curriculares do Ensino Médio e as Diretrizes Curriculares Nacionais Ensino Médio que tratam dos princípios da reforma curricular, compreendendo um processo continuo na prática na escola. Para compreender os caminhos que foram trilhados para a atual reforma do Ensino Médio, no seguinte tópico abordaremos algumas orientações que norteiam a sua gestão e suas diretrizes.

\section{Orientações normativo-legais que norteiam a gestão do ensino médio anterior e pós reforma}

No Brasil, o ensino médio, no decurso de sua história, tem sido constantemente tema de discussão/reflexão sobre o seu real papel e/ou função para educação, e aqui se destaca a gestão democrática aplicada nesta etapa de ensino. Na busca de compreender tal cenário, é importante explanar brevemente sua historicidade.

Moehlecke (2012, p.2) destaca que inicialmente organizado com base no modelo de seminário escola dos jesuítas, o ensino médio no Brasil nasce como um lugar para poucos, preparado apenas para as elites, com objetivo de adentrar aos cursos superiores. Algumas mudanças surgiram com as reformas educacionais na década de 1930, sendo implantado o ensino profissionalizante destinado a preparar mão de obra para as indústrias que começavam a surgir no país. Paralelamente, preservou-se o ensino de caráter propedêutico, destinado ao ingresso ao ensino superior.

Os estudos demonstram que a estrutura organizacional do ensino médio teve inicialmente a proposta de formação profissional destinada aos trabalhadores instrumentais, passou também a contar com alternativas em nível médio de segundo ciclo: o agrotécnico, o comercial técnico, o industrial técnico e o normal, os quais não davam acesso ao ensino superior. Todavia, percebe-se uma tentativa de articulação entre as modalidades científica e clássica e as profissionalizantes, por meio da abertura de possibilidade dos estudantes dos cursos profissionalizantes de prestarem exames de adaptação que lhes dariam o direito a 
participar dos processos de seleção para o ensino superior (MOEHLECKE, 2012).

Quanto à estrutura organizacional do ensino médio, está vem sofrendo alterações desde a edição da Lei de Diretrizes e Bases da Educação Nacional (Lei no 4.024/1961), em atendimento às mudanças ocorridas no mundo do trabalho daquele período. Pela primeira vez, a lei reconheceu a integração entre o ensino profissional e o ensino regular de $2^{\circ}$ grau com o estabelecimento da equidade entre os cursos profissionalizantes e os propedêuticos para fins de prosseguimento de estudos. Todavia, a dualidade estrutural permaneceu porque continuaram a existir dois ramos distintos de ensino. Com o passar de outras reformas (Lei $n^{\circ}$ 5.692/1971) deu-se continuidade a dualidade de função do ensino médio (MOEHLECKE, 2012).

As alterações relevantes e fundamentais se deram com a aprovação da Constituição Federal de 1988, no caráter do nível de ensino em pauta. Afirmou-se o dever do Estado em asseverar a "progressiva extensão da obrigatoriedade e gratuidade do ensino médio" (Art. 208, inciso II), indicando-se a intenção de estendê-lo a toda a população, medida que se refletiu no processo de ampliação da oferta do ensino médio, ocorrida nos anos que se seguiram.

Tais alterações se afirmaram com a Lei de Diretrizes e Bases de 1996 determinando que o Ensino Médio é a etapa final da educação básica, com duração mínima de três anos, tendo como finalidades abrangentes (BRASIL, 1996), disposto no parágrafo $2^{\circ}$ do Art. $1^{\circ}$, "a educação escolar deverá vincular-se ao mundo do trabalho e à prática social".

No art. 35, da mesma lei, coloca como finalidades para o ensino médio: a consolidação e o aprofundamento dos conhecimentos adquiridos no ensino fundamental para fins de prosseguimento dos estudos; preparação básica para o trabalho e a cidadania do educando de modo que ele possa ser capaz de se adaptar com flexibilidade a novas condições de ocupação ou aperfeiçoamento posteriores; aprimoramento do educando como pessoa humana, incluindo a formação ética e o desenvolvimento da autonomia intelectual e do pensamento crítico; e a compreensão dos fundamentos científico-tecnológicos dos processos produtivos, relacionando a teoria com a prática, no ensino de cada disciplina (BRASIL, 1996).

Sobre esses artigos, entende-se que esta etapa do ensino, possui duas funções, preparar para o trabalho futuro e dar continuidade aos estudos.

Em relação à extensão do ensino médio como etapa obrigatória, a Ementa Constitucional $\mathrm{n}^{\circ} 59$ de 2009 altera o texto da CF/1988 ao afirmar como dever do Estado assegurar a "progressiva extensão da obrigatoriedade e gratuidade do ensino médio" (art. 208, inciso II), indicando-se a intenção de estendê-lo a toda a população, embora esta medida atenta ao princípio de obrigatoriedade (direito público subjetivo) somente a faixa etária de 17 anos, mas no que diz respeito ao atendimento, esta medida reflete o processo de ampliação da oferta 
do ensino médio, ocorrida nos anos que se seguem.

A LDB de 1996 reafirma o texto legal da Carta Magna, consagrando o ensino médio como etapa final da educação básica, tendo objetivos abrangentes (Art. 35) que englobam a formação para a continuidade dos estudos, o desenvolvimento da cidadania e do pensamento crítico, assim como a preparação técnica para o trabalho, assegurado à formação geral. Entendese desde então, o sentido de romper a dualidade que envolve o ensino para o trabalho e/ou ensino superior.

Desde então, houve uma expansão da oferta do ensino médio em todo o país e definiuse que era preciso uma nova formulação de concepção da mesma, e que era essencial a participação da comunidade escolar nessas reformas (BRASIL/PCNEM, 2000, p. 4). Aqui fica subentendido a gestão democrática, tendo em vista a participação da comunidade escolar na tomada de decisão sobre tais reformas. No entanto tais reformas são objetos de debates no país todo, demonstrando contradições quanto a sua aplicabilidade.

No que diz respeito a organização do currículo nesta etapa, desde anos de 1990 há orientações normativas (não mandatórias) que discriminam propostas curriculares de atuação, como as Diretrizes Curriculares Nacionais Ensino Médio (DCNEM) Parecer CNE/CEB nº 15 e Resolução no 3 ambos de 1998; os Parâmetros Curriculares Nacionais do Ensino Médio (PCNs) de 2000; Parecer CNE/CEB nº 05/2011 DCNEM (substitui o Parecer e a Resolução anteriores); Diretrizes Curriculares Nacionais Gerais para a Educação Básica Parecer CNE/CEB no 7/2010 e Resolução CNE/CEB n 4/2010; Diretrizes Curriculares Nacionais para a Educação Profissional Técnica de Nível Médio (Parecer CNE/CEB nº 11/2012), que já anunciavam pautas de discussões sobre o projeto de reforma do ensino médio. Tais propostas e orientações surgem das demandas da conjuntura econômica-social do país, decorrentes das novas tecnologias e das mudanças na produção de bens, serviços e conhecimentos exigindo que a escola possibilite aos alunos integrarem-se ao mundo contemporâneo nas dimensões fundamentais da cidadania e do trabalho.

A atual orientação advinda da instituição da Lei no 13.415 de 2017, altera a LDB/1996 e a Lei $n^{\circ} 11.494 / 2007$, que regulamenta o Fundo de Manutenção e Desenvolvimento da Educação Básica e de Valorização dos Profissionais da Educação (FUNDEB), a Consolidação das Leis do Trabalho (CLT), aprovada pelo Decreto-Lei $n^{\circ} 5.452 / 1943$, e o Decreto-Lei $n^{\circ}$ 236/1967; revoga a Lei n 11.161/2005; e institui a Política de Fomento à Implementação de Escolas de Ensino Médio em Tempo Integral. A reforma apresenta uma abordagem modernizante e integrada de currículo, no que se refere ao ensino médio, dois fatores se destacam na reforma desta etapa de ensino: 
Primeiramente, o fator econômico se apresenta e se define pela ruptura tecnológica característica da chamada terceira revolução técnico-industrial, na qual os avanços da microeletrônica têm um papel preponderante, e, a partir década de 80 , se acentuam no País. A denominada "revolução informática" promove mudanças radicais na área do conhecimento, que passa a ocupar um lugar central nos processos de desenvolvimento, em geral. [...] Pensar um novo currículo para o Ensino Médio coloca em presença estes dois fatores: as mudanças estruturais que decorrem da chamada "revolução do conhecimento", alterando o modo de organização do trabalho e as relações sociais; e a expansão crescente da rede pública, que deverá atender a padrões de qualidade que se coadunem com as exigências desta sociedade. (BRASIL, PCNE, 2000, p. 6).

As justificativas para elaboração de novas diretrizes curriculares para o ensino médio estão anunciadas no parecer CNE/CEB n. 5/2011 e dizem respeito a mudanças recentes na legislação e política educacionais, tais como a criação do Fundo de Manutenção e Desenvolvimento da Educação Básica e de Valorização dos Profissionais da Educação (FUNDEB) e a ampliação da obrigatoriedade da escolarização, resultante da emenda constitucional n. 59, de novembro de 2009. Segundo o Parecer estes fatos já são indicativos para elaboração de novas diretrizes educacionais. O Parecer ainda justifica a reforma:

Em virtude nas novas exigências educacionais decorrentes da aceleração da produção de conhecimentos, da ampliação do acesso às informações, da criação de novos meios de comunicação, das alterações do mundo do trabalho, e das mudanças de interesse dos adolescentes e jovens, sujeitos dessa etapa educacional. (BRASIL, 2011, p. 1)

Em outro ponto, destaca-se a relação entre os jovens, a escola e seus anseios em relação ao trabalho:

O desencaixe entre a escola e os jovens não deve ser visto como decorrente, nem de uma suposta incompetência da instituição, nem de um suposto desinteresse dos estudantes. As análises se tornam produtivas à medida que enfoquem a relação entre os sujeitos e a escola no âmbito de um quadro mais amplo, considerando as transformações sociais em curso. Essas transformações estão produzindo sujeitos com estilos de vida, valores e práticas sociais que os tornam muito distintos das gerações anteriores. Entender tal processo de transformação é relevante para a compreensão das dificuldades hoje constatadas nas relações entre os jovens e a escola. (BRASIL, 2011, p. 13).

Entende-se que o Parecer busca dar novos sentidos aos saberes para a escola, parte do reconhecimento de que as novas diretrizes para o ensino médio estão ancoradas na necessidade de conferir outra dinâmica a essa etapa da educação básica e de buscar novas formas de organização do currículo com vistas à ressignificação dos saberes escolares para que sejam capazes de conferir qualidade e ampliar a permanência dos jovens na escola. Nesse sentido, o texto normativo traz um conjunto de argumentações que buscam qualificar e contextualizar suas proposições: a educação como direito social; o ensino médio com qualidade social; o sentido 
da escola para as "juventudes"; as especificidades do ensino médio noturno, da educação de jovens e adultos, dos quilombolas, indígenas e do campo, dos estudantes da educação especial estão entre os argumentos que explicam as propostas para a organização curricular segundo essas diretrizes:

O debate sobre a atualização das Diretrizes Curriculares Nacionais para o Ensino Médio deve, portanto, considerar importantes temáticas, como o financiamento e a qualidade da Educação Básica, a formação e o perfil dos docentes para o Ensino Médio e a relação com a Educação Profissional, de forma a reconhecer diferentes caminhos de atendimento aos variados anseios das "juventudes" e da sociedade. (BRASIL, 2011, p. 4).

Sendo assim, os pressupostos e fundamentos para um ensino médio considerado de qualidade social e que atenda às finalidades destacadas acima estão o trabalho, a ciência, a tecnologia e a cultura como dimensões da formação humana, tendo a teoria e prática no cotidiano escolar, que permitiria conhecer uma dada realidade e intervir nela. Com as discussões e definições do Parecer citado acima, constituem-se em orientações normativas e prescritivas para a oferta e organização curricular do ensino médio presentes na resolução CNE/CEB n. 2/2012 (BRASIL, 2012, p. 2):

Art. $5^{\circ} \mathrm{O}$ ensino médio, em todas as suas formas de oferta e organização, baseia-se em: I - formação integral do estudante; [...] VIII - integração entre educação e as dimensões do trabalho, da ciência, da tecnologia e da cultura como base da proposta e do desenvolvimento curricular.

Com as devidas orientações normativas apresentadas pelos Pareceres acima citados, foi aprovada a Lei $n^{\circ} 13.415$, de 16 de fevereiro de 2017, que altera as Leis $n^{\text {os }}$ 9.394, de 20 de dezembro de 1996, que estabelece as diretrizes e bases da educação nacional e 11.494, de 20 de junho 2007, que regulamenta o Fundo de Manutenção e Desenvolvimento da Educação Básica e de Valorização dos Profissionais da Educação, a Consolidação das Leis do Trabalho (CLT), aprovada pelo Decreto-Lei $\mathrm{n}^{\mathrm{0}}$ 5.452, de $1^{\underline{0}}$ de maio de 1943 e o Decreto-Lei $\mathrm{n}^{\mathrm{o}}$ 236, de 28 de fevereiro de 1967; revoga a Lei n-11.161, de 5 de agosto de 2005; e institui a Política de Fomento à Implementação de Escolas de Ensino Médio em Tempo Integral. O texto aprovado divide o conteúdo do Ensino Médio em duas partes: 60\% para disciplinas comuns a todos, a serem definidas pela Base Nacional Comum Curricular (BNCC) e 40\% para que o aluno aprofunde seus conhecimentos em uma área de interesse, entre as opções Linguagens, Matemática, Ciências Humanas, Ciências da Natureza e Ensino Profissional. Anteriormente eram 13 disciplinas obrigatórias ao longo dos três anos do Ensino Médio. 
A oferta de turno integral de 800 horas, antes definida na LDB/1996, passa para 1,4 mil horas anuais (progressivamente), mediante financiamento da União junto aos Estados e ao Distrito Federal. O Ensino Médio passa a ser com percursos formativos divididos em módulos e, especificamente no ensino técnico, há a possibilidade de conceder certificados intermediários, antes esta etapa do ensino era dívida em três anos. As principais alterações estão na grade curricular que colocam as disciplinas de Filosofia, Sociologia, Educação Física e Artes funcionarão como matérias "optativas".

As escolas oferecerão as matérias, mas ficará a cargo do aluno escolher estudar as disciplinas ou não, pela LDB/1996, o estudo de tais disciplinas eram obrigatórias. A nova reforma ainda restringe a obrigatoriedade do ensino da arte e da educação física à educação infantil e ao ensino fundamental, tornando-as facultativas ao ensino médio. Ainda torna o ensino da língua inglesa a partir do sexto ano do ensino fundamental e nos currículos do ensino médio, facultando neste, o oferecimento de outros idiomas, preferencialmente o espanhol.

A reforma permite que os conteúdos cursados no ensino médio sejam aproveitados no ensino superior. O currículo do ensino médio será composto pela Base Nacional Comum Curricular - BNCC e por itinerários formativos específicos definidos em cada sistema de ensino e com ênfase nas áreas de linguagens, matemática, ciências da natureza, ciências humanas e formação técnica e profissional:

Art. 35-A. A Base Nacional Comum Curricular definirá direitos e objetivos de aprendizagem do ensino médio, conforme diretrizes do Conselho Nacional de Educação, nas seguintes áreas do conhecimento:

I - linguagens e suas tecnologias;

II - matemática e suas tecnologias;

III - ciências da natureza e suas tecnologias;

IV - ciências humanas e sociais aplicadas. (BRASIL, 2017).

A LEI Dá autonomia às instituições de ensino para definir a organização das áreas de conhecimento, as competências, habilidades e expectativas de aprendizagem definidas na BNCC. Quanto os profissionais da educação que atuarão, anteriormente somente docentes que fizeram cursos de formação de professores podem lecionar, agora com a reforma docentes de "notório saber" para o ensino técnico e profissional; profissionais graduados em outras áreas, mediante cursos curtos de formação pedagógica; professores formados não só em universidades e institutos superiores, mas também em "faculdades isoladas":

IV - profissionais com notório saber reconhecido pelos respectivos sistemas de ensino, para ministrar conteúdos de áreas afins à sua formação ou experiência profissional, atestados por titulação específica ou prática de ensino em unidades educacionais da rede pública ou privada ou das corporações privadas em que tenham atuado, exclusivamente para atender ao inciso $\mathrm{V}$ do caput do art. 36; 
V - profissionais graduados que tenham feito complementação pedagógica, conforme disposto pelo Conselho Nacional de Educação. (BRASIL, 2017).

Desde o início do projeto de reforma, muitas discussões a respeito das mudanças que foram feitas. As atualizações são apresentadas desde as DCNEM de 1998, compreendida como essenciais diante das mudanças no cenário educacional do país nos últimos anos, bem como as transformações ocorridas na sociedade. $\mathrm{O}$ debate ainda e amplo diante das questões que permeiam a especificidade desta etapa de ensino e suas respectivas políticas curriculares.

As DCNEM - Parecer CNE/CEB nº 05/2011 e Resolução n CNE/CEB nº 2/2012 têm como proposição principal a integração curricular em torno do eixo ciência, cultura, trabalho e tecnologia, ao possuir como fundamento o princípio educativo do trabalho.

Em seu artigo $5^{\circ}$ (BRASIL, 2012) estabelece-se que o Ensino Médio deve basear-se em:

I - formação integral do estudante;

II - trabalho e pesquisa como princípios educativos e pedagógicos, respectivamente;

III - educação em direitos humanos como princípio nacional norteador;

IV - sustentabilidade ambiental como meta universal;

V - indissociabilidade entre educação e prática social [...];

VI - integração de conhecimentos gerais e, quando for o caso, técnicoprofissionais realizada na perspectiva da interdisciplinaridade e da contextualização;

VII - reconhecimento e aceitação da diversidade e da realidade concreta dos sujeitos do processo educativo [...];

VIII - integração entre educação e as dimensões do trabalho, da ciência, da tecnologia e da cultura como base da proposta e do desenvolvimento curricular.

Destaca-se que a flexibilização curricular, que perpassa pelas mudanças dos tempos, a organização dos espaços e práticas pedagógicas e, sobretudo, a revisão do currículo, se insere no contexto das implicações de como será realizado a gestão destas. Nesse contexto de reorganização, advinda das reformas, entende-se que os obstáculos que já fazem parte do cenário educacional desde os primórdios, como: formação docente; estruturas físicas limitadas que dificultam mostrar a relações entre teoria e prática; a autonomia para as escolas em suas escolhas pedagógicas, etc.

Fica evidente que o discurso de gestão democrática evidenciada nos documentos citados nesta pesquisa, que orientam para tal, está presente. No entanto precisa ser posta em prática, visto que as reformas realizadas foram pouco debatidas, visando à efetivação das diretrizes para atingir uma formação humana integral. Desde a LDB/1996 as orientações já são para uma educação voltada a uma gestão democrática. As reformas atuais foram bastante criticadas por grupos e entidades ligadas à educação, que defendem uma maior discussão das mudanças. Além de ter acontecido diversas mobilizações de estudantes e professores que decidiram 
entrar em greve, pedindo a rejeição da MP, tanto pela falta de discussão quanto pelo conteúdo.

\section{Considerações finais}

A gestão escolar demanda, sobretudo, de um trabalho coletivo que busque um debate democrático para que as tomadas de decisão possam ser mais conscientes e críticas. Nessa perspectiva destacamos a importância de: conhecer as necessidades e as expectativas do grupo ao qual pertencemos; compreender mais a fundo os pontos de vista que recuperem o interesse institucional e social; promover a gestão democrática por meio do envolvimento participativo e coletivo como um processo valioso de prática social e educativa e, de organização do trabalho pedagógico como um todo.

Tal estudo revela ainda que a gestão escolar com intenções democratizantes é possível. As propostas e projetos discutidos, planejados e decididos em conjunto de modo participativo ganha vida e se materializa quando são pensados e deliberados pelo coletivo. Quando os objetivos são definidos pela equipe como um todo, estes são assumidos e concretizados por fazerem parte das reais intenções do grupo e da instituição escolar. Cabe problematizar em que medida as recentes reformas educacionais impactam nas propostas de nas práticas de gestão democrática, que conforme demonstra a produção da área tem dificuldades em se consolidar para além dos normativos legais.

O estudo possibilitou perceber que em todas as reformas, resoluções implementadas após a LDB/1996, mantém a importância da gestão democrática para efetivação das diretrizes e orientações para o Ensino Médio. Diante disso, as orientações percebidas nos documentos nos possibilita enxergar caminhos diversos para o planejamento da estrutura de aprendizagem realizada nas instituições escolares do Ensino Médio e encontrar meios de efetivar a gestão democrática definida nas leis. No que diz respeito ao trato da gestão escolar após a reforma os documentos continuam reafirmando o que a LDB já trazia, gestão democrática, participativa e emancipatória. No entanto perante tantas discussões, polêmicas e mudanças ocorridas, nota-se que a reforma não se deu de maneira democrática. Debates amplos, não aconteceram efetivamente, ficando apenas no papel essa democratização de tomada de decisões.

Explicitar esses aspectos na gestão escolar significa fazer referência às múltiplas relações que se estabelecem entre os diferentes sujeitos envolvidos no trabalho educacional. Nesse sentido, o espaço de gestão constituído e efetivado serve como mecanismo de reconhecimento dessas relações. As pesquisas são importantes para despertar reflexões, bem 
como colaborar com os conhecimentos sobre a prática docente, tentando a principio articular conhecimentos teóricos e práticos.

Por meio da pesquisa surgiram reflexões sobre as condições reais da gestão escolar e destaca a tarefa de ampliar e aprofundar os debates teóricos sobre o tema. Deste modo, foi importante privilegiar um trabalho que considere a diversidade de instrumentos viabilizadores de uma gestão participativa e reflexiva. Ainda que, os desafios sejam enormes e constantes na educação, esperamos que este estudo apresente-se como fonte relevante para futuras pesquisas da área e que contribua efetivamente para a valorização e reconhecimento da gestão democrática como prática participativa. Portanto, a prática de gestão (democrática) possibilita que, de maneira reflexiva e crítica, se estabeleçam relações entre a proposta em andamento e aquilo que é preconizado nas definições legais.

\section{REFERÊNCIAS}

BRASIL. Ministério da Educação. Lei de Diretrizes e Bases da Educação Nacional. Lei n ${ }^{\circ}$ 9.394/96, de 20 de dezembro de 1996. Disponível em: <www.planalto.gov.br/ccivil_03/LEIS/19394.htm> Acesso em: ago. 2017.

BRASIL. Ministério da Educação. Conselho Nacional de Educação Câmara de Educação Básica 30 de Janeiro 2012. Diretrizes Curriculares do Ensino Médio. Disponível em: $>$ http://portal.mec.gov.br/index.php?option=com_docman\&view=download\&alias=9864rceb002-12\&Itemid=30192>. Acesso em: ago. 2017.

BRASIL. Ministério da Educação. Parâmetros Curriculares Nacionais do Ensino Médio 2000. Disponível em: < http://portal.mec.gov.br/seb/arquivos/pdf/blegais.pdf>. Acesso em: ago. 2017

BRASIL. Ministério da Educação. Parecer CNE/CEB n. ${ }^{\circ}$ 15/98, de 01 de junho de 1998. Dispõe sobre as Diretrizes Curriculares Nacionais para o ensino médio. Relatora: Conselheira Guiomar Namo de Mello. Disponível em:

<http://www.planalto.gov.br/ccivil_03/constituicao/ConstituicaoCompilado.htm.>. Acesso em: jun. 2017.

BRASIL. Ministério da Educação. Parecer $n^{\circ} 07$, de 09 de julho de 2010. Trata da revisão das Diretrizes Curriculares Nacionais Gerais para Educação Básica. MEC/SEB, 2010a.

Disponível em: <http://portal.mec.gov.br/docman/julho-2013-pdf/13677-diretrizes-educacaobasica-2013-pdf/file >. Acesso em: jun. 2017.

BRASIL. Ministério da Educação. Resolução no 4, de 13 de julho de 2010. Institui as Diretrizes Curriculares Nacionais Gerais para Educação Básica. Brasília: MEC/SEB, 2010b. Disponível em: <http://portal.mec.gov.br/docman/julho-2013-pdf/13677-diretrizes-educacaobasica-2013-pdf/file >. Acesso em: jun. 2017.

BRASIL. Ministério da Educação. Lei $n^{\circ} 13.145$, de 16 de fevereiro de 2017. Altera a Leis $n^{\circ}$ 9.394, de 20 de dezembro de 1996, que estabelece as diretrizes e bases da educação nacional. Disponível em: <http://www.planalto.gov.br/ccivil_03/_ato2015-2018/2017/lei/113415.htm> Acesso em: jun. 2017. 
CERVO, A. L.; BERVIAN, P. A.; SILVA, R. da. Metodologia Científica. 6. ed. São Paulo: Pearson Prentice Hall, 2007.

CURY, C. R. J. Gestão democrática da educação: experiências e desafios. Revista brasileira de política e gestão da educação, ANPAE, São Bernardo do Campo, v. 18, n. 2, p.163-174, jul./dez. 2002. Disponível em:

<http://www.seer.ufrgs.br/rbpae/article/viewFile/25486/14810>. Acesso em: jun. 2017.

GIGLIO C. M. B.; JACOMINI, M. A. Gestão da escola e organização do trabalho pedagógico. In: SCAFF, E. A. da S.; LIMA, P. G.; ARANDA, M. A. de M. (Orgs.). Política e gestão da educação básica: desafios à alfabetização. São Paulo: Expressão e Arte Editora, 2013.

LIBÂNEO, J. C.; OLIVEIRA, J. F. de; TOSCHI, M. S. Educação escolar: políticas, estrutura e organização. 6. ed. São Paulo: Cortez, 2010.

MOEHLECKE, Sabrina. Revista Brasileira de Educação, v. 17 n. 49, jan./abr. 2012. Disponível em: 〈http://www.scielo.br/pdf/rbedu/v17n49/a02v17n49.pdf >. Acesso em: ago. 2017

SILVA, J. B. da. Um olhar histórico sobre a gestão escolar. Educação em Revista Marília, v. 8, n. 1, p. 21-34, 2007. Disponível em:

<http://www2.marilia.unesp.br/revistas/index.php/educacaoemrevista/article/view/616/499>. Acesso em: jun. 2017.

PARO, V. H. A educação, a política e a administração: reflexões sobre a prática do diretor de escola. Educação \& Pesquisa, [online], São Paulo, v. 36, n. 3, p. 763-778, set./dez. 2010. Disponível em:

<http://www.scielo.br/scielo.php?pid=S151797022010000300008\&script=sci_abstract\&tlng= pt>. Acesso em: jun. 2017.

PARO, V. H. O princípio da gestão escolar democrática no contexto da LDB. In: MINTO, C. A.; OLIVEIRA, R. P. de; ADRIÃO, T. (Orgs.). Gestão, financiamento e direito à educação: análise da LDB e da Constituição Federal. São Paulo: Xamã, 2007.

SALLES, F.; FARIA, V. Currículo: diálogo com demais elementos da proposta pedagógica. 2. ed. São Paulo: Ática, 2012.

VEIGA, I. P. A. Projeto político-pedagógico da escola: uma construção coletiva. In:

(Org.). Projeto político-pedagógico da escola: uma construção possível. 14 ed. São Paulo: Papirus, 2002.

VEIGA, I. P. A. Projeto político-pedagógico: novas trilhas para a escola. In: VEIGA, I. P. A. et al. (Orgs.). As dimensões do Projeto Político-Pedagógico. 5. ed. Campinas, SP: Papirus, 2007.

Artigo recebido em: 26/04/2018

Artigo aceito em: 16/05/2018 